\title{
Lactobacillus nodensis sp. nov., isolated from rice bran
}

\author{
Tomoko Kashiwagi, Tomonori Suzuki and Takashi Kamakura \\ Department of Applied Biological Science, Tokyo University of Science, Chiba 278-8510, Japan
}

Correspondence

Takashi Kamakura

kamakura@rs.noda.tus.ac.jp

\begin{abstract}
Gram-positive, rod-shaped, non-motile lactic acid bacteria, strains iz $4 b-1^{\top}$, iz $4 b-2$ and iz4c-1, were isolated in an attempt to study the composition of the Lactobacillus flora of Japanese pickles. Analysis of their 16S rRNA gene sequences revealed that the strains clustered in the Lactobacillus alimentarius group, and comparatively high similarities were shown to 'Lactobacillus tucceti' CECT 5920 (97.0\%), Lactobacillus versmoldensis $\mathrm{KU}-3^{\top}$ (96.4\%) and Lactobacillus nantensis LP33 $^{\top}(94.4 \%)$. DNA-DNA hybridization assays clearly revealed that the isolates represented a novel taxon. The DNA G $+\mathrm{C}$ content was $40.6 \mathrm{~mol} \%$ and the peptidoglycan type was L-Lys-D-Asp. Thus, these isolates represent a novel Lactobacillus species, for which the name Lactobacillus nodensis sp. nov. is proposed. The type strain is iz4b-1 ${ }^{\top}$ (=DSM $19682^{\top}$ $=\mathrm{JCM} 14932^{\top}$ ).
\end{abstract}

Lactic acid bacteria (LAB) play important roles in vegetable fermentations by producing lactic acid and/or alcohol, which improve the taste of pickles and help to preserve them. Many kinds of LAB, such as Lactobacillus plantarum, Lactobacillus brevis, Leuconostoc mesenteroides and Pediococcus acidilactici, are found widely in the various stages of fermentation. We have studied the LAB flora of a Japanese homemade pickle called nuka-zuke, which is made by pickling vegetables and rice bran paste, and isolated 103 strains from 15 independent pickle samples. $16 \mathrm{~S}$ rRNA gene sequences of all the isolates were analysed and three strains, iz $4 b-1^{\mathrm{T}}$, iz $4 \mathrm{~b}-2$ and iz $4 \mathrm{c}-1$, showed low levels of sequence similarity to any other established species. Therefore, additional tests were performed to determine whether these three strains represented a novel Lactobacillus species.

The strains were isolated from nuka-zuke made in Utsunomiya city, Tochigi prefecture, Japan. Samples were homogenized in $0.85 \% \mathrm{NaCl}$ solution, serially diluted and spread on MRS (Oxoid) agar plates. Plates were incubated at $30{ }^{\circ} \mathrm{C}$ for $48 \mathrm{~h}$. Colonies were picked and isolates were grown routinely in MRS broth or agar and maintained at $-80{ }^{\circ} \mathrm{C}$ as glycerol stocks.

Chromosomal DNA was extracted as described by Pitcher et al. (1989) and used as a template for 16S rRNA gene sequence amplification. Primers of (5'-AGAGTTTGAT-

Abbreviation: $L A B$, lactic acid bacteria.

The GenBank/EMBL/DDBJ accession number for the 16S rRNA gene sequence of strain iz $4 b-1^{\top}$ is $A B 332024$.

$16 \mathrm{~S}$ rRNA gene sequence-based maximum-parsimony and maximumlikelihood trees and detailed DNA-DNA hybridization results are available as supplementary material with the online version of this paper.
CCTGGCTCAG-3') and 1540r (5'-AAGGAGGTGATCCAGCCGCA-3') were used for PCR (Endo \& Okada, 2005). The PCR products were purified using QIAquick PCR purification kit (Qiagen) according to the manufacturer's instructions. Cycle sequencing was performed with a BigDye Terminator v3.1 cycle sequencing kit (Applied Biosystems) and seven primers listed in Endo \& Okada (2005). The sequences were analysed and the closest recognized relatives of the isolates were searched for in the NCBI database using the BLAST program (http:// www.ncbi.nlm.nih.gov/BLAST/). Sequences representing the closest matches were retrieved and then aligned using the CLUSTAL W program (Thompson et al., 1994). All sequences used in the reconstruction of the phylogenetic tree were approximately 1560 bp long. A distance matrix was calculated using Kimura's two-parameter model (Kimura, 1980). Phylogenetic trees were constructed with the neighbour-joining method as described by Saitou \& Nei (1987) and the maximum-parsimony method as described by Felsenstein (1978) using the software package MEGA version 4.0 (Tamura et al., 2007) and the maximumlikelihood method (Felsenstein, 1981) using PHYLIP version 3.67 (Felsenstein, 2007). Statistical significance of groupings was estimated by bootstrapping (1000 replicates). The maximum-parsimony and maximum-likelihood trees are available as Supplementary Figs S1 and S2 in IJSEM Online.

The $\mathrm{G}+\mathrm{C}$ contents of the strains were determined by HPLC as described by Katayama-Fujimura et al. (1984). DNA-DNA hybridizations were carried out in triplicate as described by Ezaki et al. (1988, 1989). Salmon sperm DNA was used as a control. The peptidoglycan type was determined as described by Schleifer \& Kandler (1972) and Schleifer (1985). 
Cell morphology of the strains was observed by phasecontrast microscopy. Determination of Gram reactions was performed using a Favor G 'Nissui' kit (Nissui) following the manufacturer's instructions. Sugar-fermentation patterns were assessed using the API 50 CHL system (bioMérieux) for $48 \mathrm{~h}$ at $30{ }^{\circ} \mathrm{C}$ according to the manufacturer's instructions after diluting the colonies with saline. Lactic acid configuration was determined using a DL-lactate test kit (Boehringer Mannheim). Catalase activity was determined by transferring fresh colonies from MRS agar to $1.5 \mathrm{ml}$ tubes containing $5 \% \mathrm{H}_{2} \mathrm{O}_{2}$. The production of gas from glucose was assayed by cultivation of the bacteria in tubes covered with $2 \%$ agar plugs above the MRS broth.

Partial 16S rRNA gene sequences (about $1560 \mathrm{bp}$ ) were obtained from strains iz $4 \mathrm{~b}-1^{\mathrm{T}}$, iz $4 \mathrm{~b}-2$ and iz4c-1. Values of sequence similarity indicated that the closest neighbours of strain iz4b-1 ${ }^{\mathrm{T}}$ were 'Lactobacillus tucceti' CECT 5920 (97.0\%), Lactobacillus versmoldensis $\mathrm{KU}-3^{\mathrm{T}}$ (96.4\%) and Lactobacillus nantensis $\mathrm{LP}^{3} 3^{\mathrm{T}}$ (94.4\%). They belong to the Lactobacillus alimentarius group (Fig. 1). The sequence similarity between strain iz $4 \mathrm{~b}-1^{\mathrm{T}}$ and strains iz $4 \mathrm{~b}-2$ and iz4c-1 was 99.7 and $99.5 \%$, respectively.

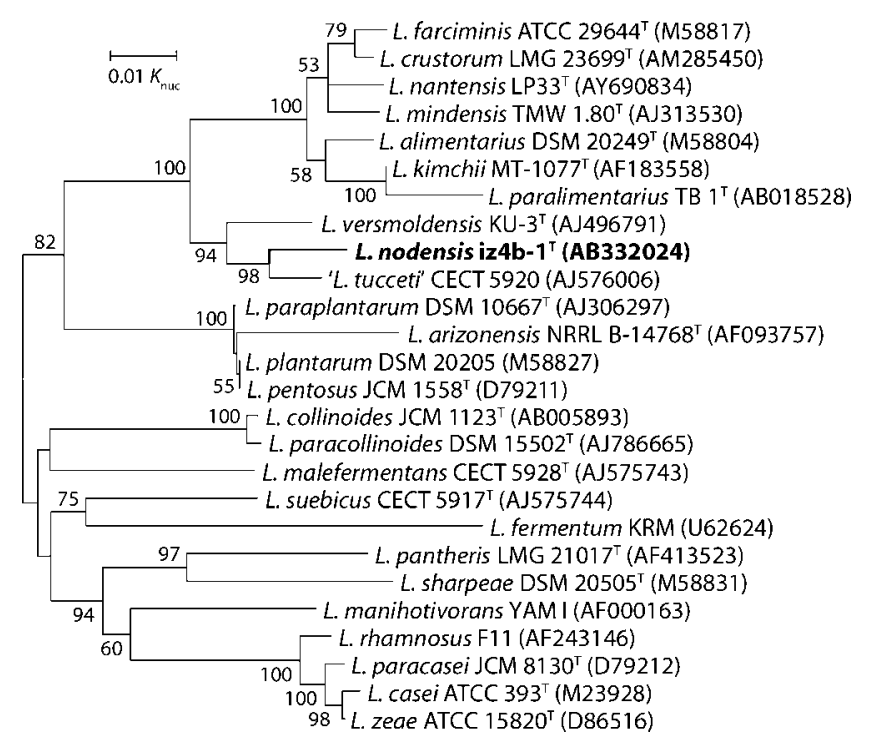

Fig. 1. Phylogenetic tree showing the relationships between strain iz $4 \mathrm{~b}-1^{\top}$ and related Lactobacillus species on the basis of $16 \mathrm{~S}$ rRNA gene sequences. The tree was constructed using the neighbour-joining method. Bootstrap values based on 1000 replications are listed as percentages at branching points; only values above $50 \%$ are indicated. Bar, $0.01 K_{\text {nuc }}$ (indicates nucleotide substitutions per site). The $L$. alimentarius group (Felis \& Dellaglio, 2007) includes L. farciminis, L. crustorum, L. nantensis, L. mindensis, L. alimentarius, L. kimchii, L. paralimentarius, $L$. versmoldensis, 'L. tucceti' and $L$. nodensis sp. nov. Maximum-likelihood and maximum-parsimony trees are shown in Supplementary Figs S1 and S2.
Strains iz $4 \mathrm{~b}-1^{\mathrm{T}}$, iz $4 \mathrm{~b}-2$ and iz4c-1 showed high levels of DNA-DNA hybridization values $(90-98 \%)$ to one another, while the type strain iz $4 \mathrm{~b}-1^{\mathrm{T}}$ showed low levels of DNA-DNA relatedness to ' $L$. tucceti' CECT 5920 (9, 14 and 19\%; Supplementary Table S1). The DNA G+C content of strain iz $4 \mathrm{~b}-1^{\mathrm{T}}$ was $40.6 \mathrm{~mol} \%$ and that of ' $L$. tucceti' CECT 5920 was $35.9 \mathrm{~mol} \%$. This value is within the range reported for the genus Lactobacillus (32-53 mol\%) by Kandler et al. (1983). The peptidoglycan type of strain iz $4 \mathrm{~b}-1^{\mathrm{T}}$ was L-Lys-D-Asp, which is the major type in the $L$. alimentarius group (Chenoll et al., 2005). Thus, we conclude that the three isolates belong to the same taxon in the $L$. alimentarius group and that the taxon is differentiated from known Lactobacillus species (Johnson, 1973; Stackebrandt \& Goebel, 1994). We are planning additional analysis to identify differences between the three strains.

Physiological and biochemical characteristics of strain iz4b-1 ${ }^{\mathrm{T}}$, 'Lactobacillus tucceti' CECT 5920 and L. versmoldensis DSM $14857^{\mathrm{T}}$ are listed in Table 1 . Strains iz $4 \mathrm{~b}-1^{\mathrm{T}}$, iz 4 b- 2 and iz4c- 1 showed almost the same patterns of sugar fermentation with the exception of D-ribose. On the basis of phylogenetic and phenotypic results, strain iz $4 \mathrm{~b}-1^{\mathrm{T}}$ is proposed as the type strain of a novel species, Lactobacillus nodensis sp. nov.

\section{Description of Lactobacillus nodensis sp. nov.}

Lactobacillus nodensis (no.den'sis. N.L. masc. adj. nodensis referring to Noda, the city in which the bacterium was originally isolated).

Cells are Gram-positive, non-motile, non-spore-forming rods, $1.8 \times 5 \mu \mathrm{m}$ in size, occurring singly or in pairs. After anaerobic growth at $30{ }^{\circ} \mathrm{C}$ for $48 \mathrm{~h}$, colonies on MRS agar are $1 \mathrm{~mm}$ in diameter, round with rough surfaces. Catalase-negative. Obligately homofermentative; gas is not produced from glucose. Both D- and L-lactic acid are produced from glucose. Growth occurs at $15-37^{\circ} \mathrm{C}$ but not at $45{ }^{\circ} \mathrm{C}$. Growth occurs at $\mathrm{pH} 4.0$ but not at $\mathrm{pH}$ 2.6. Grows in the presence of up to $15 \% \mathrm{NaCl}$ in MRS broth. Acid is produced from D-arabinose, D-ribose (straindependent weak reaction), D-galactose, D-glucose, Dfructose, D-mannose, $\mathrm{N}$-acetylglucosamine and aesculin. No acid is produced from erythritol, L-arabinose, DLxylose, adonitol, methyl $\beta$-D-xyloside, sorbose, rhamnose, cellobiose, maltose, lactose, melibiose, sucrose, trehalose, melezitose, raffinose, gentiobiose, turanose, D-lyxose, Dtagatose, DL-fucose, DL-arabitol, glycerol, dulcitol, inositol, mannitol, sorbitol, methyl $\alpha$-D-mannoside, methyl $\alpha$-Dglucoside, amygdalin, arbutin, salicin, inulin, starch, glycogen, xylitol, gluconate, 2-ketogluconate or 5-ketogluconate. The DNA $\mathrm{G}+\mathrm{C}$ content of the type strain is $40.6 \mathrm{~mol} \%$. The peptidoglycan is of the L-Lys-D-Asp type.

The type strain is strain iz4b- $1^{\mathrm{T}}\left(=\mathrm{DSM} 19682^{\mathrm{T}}=\mathrm{JCM}\right.$ $\left.14932^{\mathrm{T}}\right)$. The type strain and reference strains iz4b-2 and iz4c-1 were isolated from Japanese pickles collected in Utsunomiya city, Tochigi prefecture, Japan. 
Table 1. Phenotypic characteristics of strain $i z 4 b-1^{\top}$ and closely related species in the $L$. alimentarius group

Strains: 1, L. nodensis sp. nov. iz4b-1 ${ }^{\mathrm{T}}$ (this study); 2, 'L. tucceti' CECT 5920 (Chenoll et al., 2005); 3, L. versmoldensis KU-3 ${ }^{\mathrm{T}}$ (Kröckel et al., 2003); 4, L. kimchii MT-1077 ${ }^{\mathrm{T}}$ (Yoon et al., 2000); 5, L. paralimentarius TB $1^{\mathrm{T}}$ (Cai et al., 1999); 6, L. farciminis DSM 20184 ${ }^{\mathrm{T}}$ (Reuter, 1983); 7, L.

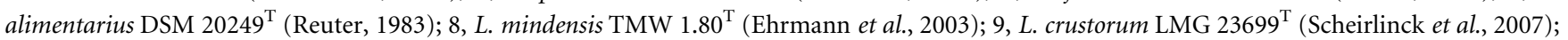
10, L. nantensis LP33 ${ }^{\mathrm{T}}$ (Valcheva et al., 2006). +, Positive; -, negative; w, weak reaction; ND, no data available.

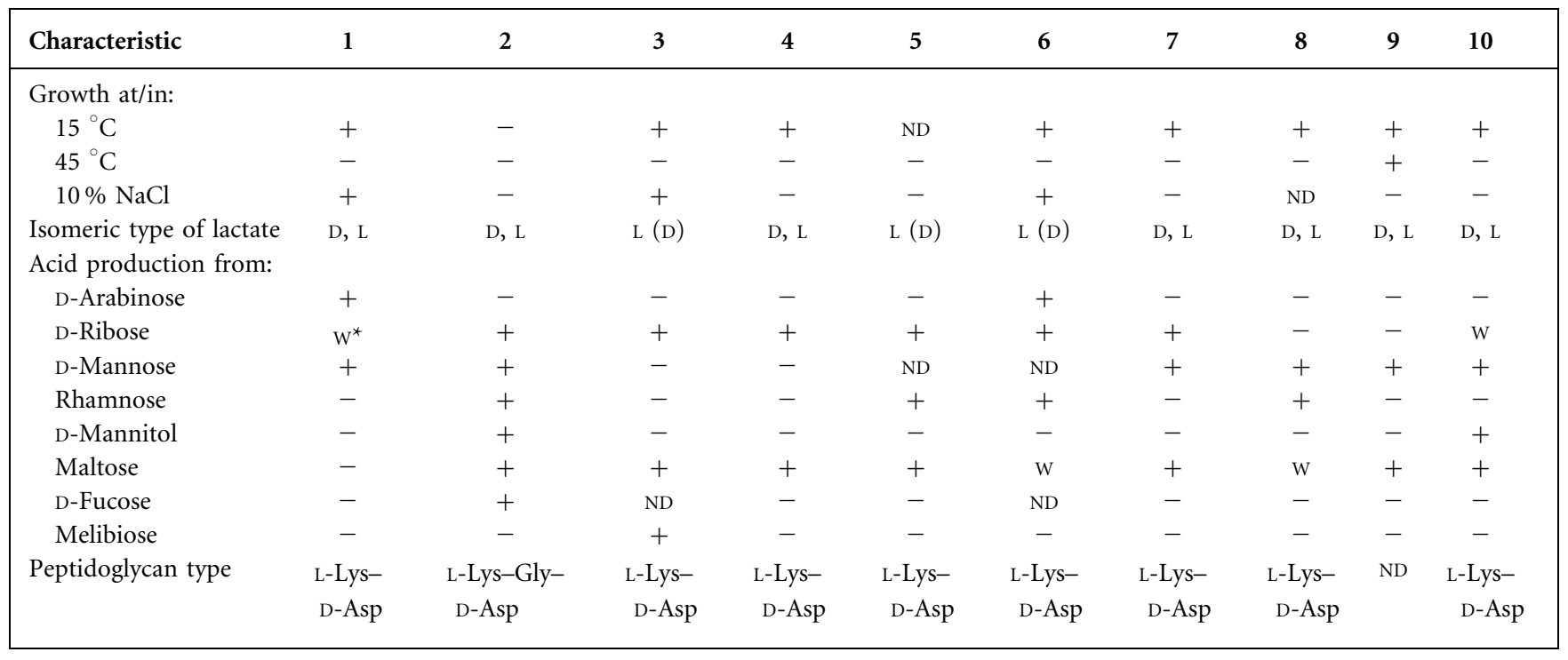

${ }^{*}$ Strain iz4c-1 was negative for D-ribose.

\section{Acknowledgements}

We are grateful to the sample supplier, Masumi Izawa. We are also grateful to Hiroshi Murata, Tokyo University of Science, and Soichiro Hyodo and Dr Makoto Kimura of the RIKEN Institute for their advice and support.

\section{References}

Cai, Y., Okada, H., Mori, H., Benno, Y. \& Nakase, T. (1999). Lactobacillus paralimentarius sp. nov., isolated from sourdough. Int J Syst Bacteriol 49, 1451-1455.

Chenoll, E., Macián, M. C. \& Aznar, R. (2005). Lactobacillus tucceti sp. nov., a new lactic acid bacterium isolated from sausage. Syst Appl Microbiol 29, 389-395.

Ehrmann, M. A., Müller, M. R. \& Vogel, R. F. (2003). Molecular analysis of sourdough reveals Lactobacillus mindensis sp. nov. Int J Syst Evol Microbiol 53, 7-13.

Endo, A. \& Okada, S. (2005). Lactobacillus satsumensis sp. nov., isolated from mashes of shochu, a traditional Japanese distilled spirit made from fermented rice and other starchy materials. Int J Syst Evol Microbiol 55, 83-85.

Ezaki, T., Hashimoto, Y., Takeuchi, N., Yamamoto, H., Liu, S.-L., Miura, H., Matsui, K. \& Yabuuchi, E. (1988). Simple genetic method to identify viridans group streptococci by colorimetric dot hybridization and fluorometric hybridization in microdilution wells. J Clin Microbiol 26, 1708-1713.

Ezaki, T., Hashimoto, Y. \& Yabuuchi, E. (1989). Fluorometric deoxyribonucleic acid-deoxyribonucleic acid hybridization in microdilution wells as an alternative to membrane filter hybridization in which radioisotopes are used to determine genetic relatedness among bacterial strains. Int J Syst Bacteriol 39, 224-229.
Felis, G. E. \& Dellaglio, F. (2007). Taxonomy of lactobacilli and bifidobacteria. Curr Issues Intest Microbiol 8, 44-61.

Felsenstein, J. (1978). Cases in which parsimony and compatibility methods will be positively misleading. Syst Zool 27, 401-410.

Felsenstein, J. (1981). Evolutionary trees from DNA sequences: a maximum likelihood approach. J Mol Evol 17, 368-376.

Felsenstein, J. (2007). PHYLIP (phylogeny inference package) version 3.67. Distributed by the author. Department of Genome Sciences, University of Washington, Seattle, USA.

Johnson, J. L. (1973). Use of nucleic-acid homologies in the taxonomy of anaerobic bacteria. Int J Syst Bacteriol 23, 308-315.

Kandler, O., Schillinger, U. \& Weiss, N. (1983). Lactobacillus halotolerans sp. nov., nom. rev. and Lactobacillus minor sp. nov., nom. rev. Syst Appl Microbiol 4, 280-285.

Katayama-Fujimura, Y., Komatsu, Y., Kuraishi, H. \& Kaneko, T. (1984). Estimation of DNA base composition by high performance liquid chromatography of its nuclease P1 hydrolysate. Agric Biol Chem 48, 3169-3172.

Kimura, M. (1980). A simple method for estimating evolutionary rates of base substitutions through comparative studies of nucleotide sequences. J Mol Evol 16, 111-120.

Kröckel, L., Schillinger, U., Franz, C. M. A. P., Bantleon, A. \& Ludwig, W. (2003). Lactobacillus versmoldensis sp. nov., isolated from raw fermented sausage. Int J Syst Evol Microbiol 53, 513-517.

Pitcher, D. G., Saunders, N. A. \& Owen, R. J. (1989). Rapid extraction of bacterial genomic DNA with guanidium thiocyanate. Lett Appl Microbiol 8, 151-156.

Reuter, G. (1983). Lactobacillus alimentarius sp. nov., nom. rev. and Lactobacillus farciminis sp. nov., nom. rev. Syst Appl Microbiol 4, 277279. 
Saitou, N. \& Nei, M. (1987). The neighbor-joining method: a new method for reconstructing phylogenetic trees. Mol Biol Evol 4, 406425.

Scheirlinck, I., Van der Meulen, R., Van Schoor, A., Huys, G., Vandamme, P., De Vuyst, L. \& Vancanneyt, M. (2007). Lactobacillus crustorum sp. nov., isolated from two traditional Belgian wheat sourdoughs. Int J Syst Evol Microbiol 57, 1461-1467.

Schleifer, K. H. (1985). Analysis of the chemical composition and primary structure of murein. Methods Microbiol 18, 123-156.

Schleifer, K. H. \& Kandler, O. (1972). The peptidoglycan types of bacterial cell walls and their taxonomic implications. Bacteriol Rev 36, 407-477.

Stackebrandt, E. \& Goebel, B. M. (1994). Taxonomic note: a place for DNA-DNA reassociation and $16 \mathrm{~S}$ rRNA sequence analysis in the present definition in bacteriology. Int J Syst Bacteriol 44, 846-849.
Tamura, K., Dudley, J., Nei, M. \& Kumar, S. (2007). MEGA4: molecular evolutionary genetics analysis (MEGA) software version 4.0. Mol Biol Evol 24, 1596-1599.

Thompson, J. D., Higgins, D. G. \& Gibson, T. J. (1994). CLUSTAL W: improving the sensitivity of progressive multiple sequence alignment through sequence weighting, position-specific gap penalties and weight matrix choice. Nucleic Acids Res 22, 4673-4680.

Valcheva, R., Ferchichi, M. F., Korakli, M., Ivanova, I., Gänzle, M. G., Vogel, R. F., Prévost, H., Onno, B. \& Dousset, X. (2006). Lactobacillus nantensis sp. nov., isolated from French wheat sourdough. Int J Syst Evol Microbiol 56, 587-591.

Yoon, J. H., Kang, S. S., Mheen, T. I., Ahn, J. S., Lee, H. J., Kim, T. K., Park, C. S., Kho, Y. H., Kang, K. H. \& Park, Y. H. (2000). Lactobacillus kimchii sp. nov., a new species from kimchi. Int J Syst Evol Microbiol 50, 1789-1795. 